\title{
Effects of baseline symptom burden on treatment response in COPD
}

This article was published in the following Dove Press journal: International Journal of COPD

\section{Fernando J Martinez' \\ Roger A Abrahams ${ }^{2,3}$ \\ Gary T Ferguson ${ }^{4}$ \\ Leif Bjermer ${ }^{5}$ \\ Lars Grönke ${ }^{6}$ \\ Florian $\mathrm{Vo}^{7}$ \\ Dave Singh ${ }^{8}$}

'Division of Pulmonary and Critical Care Medicine, Weill Cornell Medical College, New York, NY, USA; ${ }^{2}$ Morgantown Pulmonary Clinical Research, Morgantown, WV, USA; ${ }^{3}$ Department of Pulmonary \& Critical Care, Mon Health Care, Morgantown, WV, USA; ${ }^{4}$ Pulmonary Research Institute of Southeast Michigan, Farmington Hills, MI, USA; ${ }^{5}$ Department of Respiratory Medicine and Allergology, Lund University, Lund, Sweden; 'Biotechnology, CSL Behring, Wiesbaden, Germany; ${ }^{7}$ Biostatistics + Data Sciences Corp., Boehringer Ingelheim Pharma GmbH \& Co. KG, Ingelheim, Germany; ${ }^{8}$ Medicines Evaluation Unit, University of Manchester, Manchester, UK
Correspondence: Fernando J Martinez Pulmonary and Critical Care Medicine, Weill Cornell Medical College, 525 East 68th St, Room M-522, New York, NY 10065, USA

$\mathrm{Tel}+\mathrm{I} 2127466420$

Fax + I 2127468793

Email fjm2003@med.cornell.edu
Rationale: In symptomatic patients with COPD, the decision whether to initiate maintenance treatment with a single agent or a combination of long-acting bronchodilators remains unclear. Objective: To investigate whether baseline symptomatic status influences response to tiotropium/olodaterol treatment.

Materials and methods: Post hoc analysis of the randomized OTEMTO ${ }^{\circledR}$ studies (NCT01964352; NCT02006732), in which patients with moderate-to-severe COPD received placebo, tiotropium $5 \mu \mathrm{g}$, tiotropium/olodaterol $2.5 / 5 \mu \mathrm{g}$, or tiotropium/olodaterol $5 / 5 \mu \mathrm{g}$ once daily for 12 weeks via the Respimat ${ }^{\circledR}$ inhaler (Boehringer Ingelheim, Ingelheim am Rhein, Germany). Impact of baseline symptomatic status (modified Medical Research Council [mMRC] score) on response to treatment with tiotropium/olodaterol $5 / 5 \mu \mathrm{g}$, tiotropium $5 \mu \mathrm{g}$, or placebo at Week 12 was assessed by St George's Respiratory Questionnaire (SGRQ) total score and response rate, transition dyspnea index (TDI) focal score and response rate, and trough forced expiratory volume in 1 second response.

Results: Tiotropium/olodaterol improved SGRQ total scores and response rates compared with placebo and tiotropium for patients with baseline mMRC scores $0-1$ and $\geq 2$. For tiotropium/ olodaterol vs tiotropium, greater improvements were observed for patients with $\mathrm{mMRC} \geq 2$ (SGRQ score adjusted mean treatment difference -3.44 [95\% CI: $-5.43,-1.46$ ]; $P=0.0007$; SGRQ response rate ORs 2.09 [95\% CI: 1.41, 3.10]; $P=0.0002$ ). Dyspnea, measured by TDI score, was consistently improved with tiotropium/olodaterol vs placebo for patients with $\mathrm{mMRC}$ scores $0-1$ and $\geq 2$ (adjusted mean treatment difference 1.63 [95\% CI: 1.06, 2.20]; $P<0.0001$ and 1.60 [95\% CI: 1.09, 2.10]; $P<0.0001$, respectively). In patients with mMRC scores $0-1$ and $\geq 2$, tiotropium/olodaterol consistently improved TDI response rate and lung function vs placebo and tiotropium.

Conclusions: Patients with COPD with more severe baseline dyspnea appear to derive greater health status benefit with tiotropium/olodaterol compared with tiotropium alone.

Keywords: tiotropium, olodaterol, COPD

\section{Plain language summary}

The Global Initiative for Chronic Obstructive Lung Disease (GOLD) therapeutic strategy suggests differential pharmacotherapeutic approaches for COPD as a function of symptom burden, using the modified Medical Research Council (mMRC) dyspnea scale or the COPD Assessment Test to differentiate between patients with a low or a high level of symptoms. When to initiate maintenance therapy with a single or combination of long-acting bronchodilators remains unclear. In this post hoc analysis, we show that those with more severe baseline dyspnea ( $\mathrm{mMRC}$ score $\geq 2$ ) derive greater health status benefit with combination bronchodilator treatment (tiotropium/olodaterol) compared with monotherapy (tiotropium). Our data support the GOLD suggestion that combination of long-acting bronchodilators is a preferable option for those with severe breathlessness. 


\section{Introduction}

A multidimensional approach to evaluating and characterizing patients with COPD has been recommended by numerous groups. ${ }^{1-3}$ Spirometric results, symptom severity, exacerbation risk, and comorbidity assessment are key to appropriate diagnosis and optimizing therapeutic management. ${ }^{1}$ The Global Initiative for Chronic Obstructive Lung Disease (GOLD) therapeutic strategy suggests the modified Medical Research Council (mMRC) dyspnea scale or the COPD Assessment Test to differentiate between low-risk (GOLD A and $\mathrm{B}$ ) patients requiring as-needed treatment and those patients requiring regular maintenance treatment with a long-acting muscarinic antagonist (LAMA) or long-acting $\beta_{2}$-agonist (LABA). ${ }^{1}$ However, when to initiate maintenance therapy with a single agent or a combination of long-acting bronchodilators remains unclear.

Tiotropium is an established once-daily LAMA that improves lung function and reduces exacerbations in patients with COPD, as well as improving patient-reported outcomes, including dyspnea and health status. ${ }^{4-10}$ Olodaterol is a LABA with a rapid onset of action that provides 24-hour bronchodilation and symptomatic benefits in patients with COPD. ${ }^{11-14}$ Tiotropium/olodaterol combination therapy has demonstrated consistent benefits vs tiotropium monotherapy in patients with moderate-to-very-severe COPD in Phase III studies, with no additional safety concerns. ${ }^{15-17}$ OTEMTO $^{\circledR}$ 1 and 2 were replicate, randomized controlled trials which demonstrated that as well as improving lung function compared with placebo and tiotropium $5 \mu \mathrm{g}$, tiotropium/ olodaterol improved health status. ${ }^{17}$ We hypothesized that patients with greater baseline dyspnea burden would experience greater improvements in clinically relevant measures with tiotropium/olodaterol vs placebo or the individual monocomponents. Using data from the OTEMTO ${ }^{\circledR}$ studies, we investigated whether symptomatic status at baseline by mMRC score ( $0-1$ vs $\geq 2)$ influences the effect of tiotropium/ olodaterol treatment on health-related health status, dyspnea, and lung function responses. An additional objective was to understand the relationship between baseline symptom severity and baseline lung function in predicting St George's Respiratory Questionnaire (SGRQ) response. Some of the results of these studies have been previously reported in the form of an abstract. ${ }^{18}$

\section{Materials and methods Study design and treatment}

The OTEMTO ${ }^{\circledR}$ studies (NCT01964352; NCT02006732) were replicate, multinational, randomized, double-blind, parallel-group, placebo-controlled trials (see Figure S1). ${ }^{17}$ Patients received one of four treatments for 12 weeks: tiotropium/olodaterol $2.5 / 5 \mu \mathrm{g}$, tiotropium/olodaterol $5 / 5 \mu \mathrm{g}$, tiotropium $5 \mu \mathrm{g}$, or placebo, all given once daily using a Respimat ${ }^{\circledR}$ inhaler.

\section{Study patients}

Study patients were eligible for inclusion if they were aged $\geq 40$ years and had moderate-to-severe COPD (GOLD II-III, post-bronchodilator forced expiratory volume in 1 second $\left[\mathrm{FEV}_{1}\right] \geq 30 \%$ and $<80 \%$ of predicted normal), $\mathrm{FEV}_{1} /$ forced vital capacity $<70 \%$ predicted, and a smoking history of $>10$ pack-years. Key exclusion criteria included a history of asthma, a COPD exacerbation, or symptoms of lower respiratory tract infection within the previous 3 months. Patients were allowed to continue inhaled corticosteroid therapy if they were on a stable dose for 6 weeks prior to screening. Open-label salbutamol was provided as rescue medication. mMRC dyspnea scale, baseline dyspnea index (BDI), and SGRQ were measured in all patients entering the study at baseline. There were no inclusion/exclusion criteria at study entry related to mMRC, BDI, or SGRQ scores at baseline.

\section{Assessments}

Baseline symptomatic status was classified according to mMRC score $0-1$ and $\geq 2$, following the suggestion of the GOLD therapeutic strategy. ${ }^{1}$ For the current work, analyses examining the impact of baseline dyspnea status on response to tiotropium/olodaterol $5 / 5 \mu \mathrm{g}$ vs tiotropium $5 \mu \mathrm{g}$ or placebo included: SGRQ total score (change at Week 12) and response rate (defined as the proportion of patients experiencing an SGRQ total score change $\geq 4.0$ points lower than the baseline total score); symptoms (transition dyspnea index [TDI] focal score [at Week 12] and response rate [defined as the proportion of patients experiencing a TDI focal score $\geq 1$ point greater than $\mathrm{BDI}]$ ); and trough $\mathrm{FEV}_{1}$ response (change at Week 12). While all study drug doses were included in the analysis models, we report results for the globally approved tiotropium/olodaterol $5 / 5 \mu \mathrm{g}$ dose vs tiotropium $5 \mu \mathrm{g}$ and placebo only.

\section{Statistical analysis}

SGRQ and TDI responders were compared using logistic regression. The adjusted mean treatment effect (tiotropium/ olodaterol $5 / 5 \mu \mathrm{g}$ minus tiotropium $5 \mu \mathrm{g}$ or placebo) for the SGRQ total score, TDI focal score, and trough $\mathrm{FEV}_{1}$ response was obtained by fitting a mixed-effect model for 
repeated measurements. Additional analyses were conducted to evaluate the robustness of the main analysis using different baseline symptom burden cutoffs (mMRC scores 0-2 and $\geq 3$ ). As some correlation has been shown between baseline mMRC and BDI scores, ${ }^{19-21}$ sensitivity analyses using BDI score (cutoff scores of $0-4$ and $\geq 5$, and $0-5$ and $\geq 6$ ) were performed to examine whether treatment effect patterns observed for mMRC cutoffs could be confirmed using a different baseline symptom measure.

The effects of baseline mMRC score and baseline lung function (via GOLD stage) on SGRQ response rate after 12 weeks were assessed using multiple logistic regression analysis. This analysis included treatment, baseline GOLD stage (II or III), and baseline mMRC score $(0-1$ and $\geq 2)$ in the model. The analysis was conducted for the full study analysis population and for the tiotropium/olodaterol $5 / 5 \mu \mathrm{g}$ treatment group.

\section{Ethics}

The trial was carried out in accordance with the principles of the Declaration of Helsinki and the International Conference on Harmonisation-Good Clinical Practice. Each patient signed an informed consent form according to the local regulatory and legal requirements.

\section{Results \\ Patients}

Overall, 1,621 patients were treated in the two OTEMTO ${ }^{\circledR}$ studies, and 1,619 had data available for mMRC and BDI. Table 1 enumerates baseline characteristics: mMRC dyspnea scale scores were $0-1$ in 736 patients (45\%), 0-2 in 1,275 patients $(79 \%), \geq 2$ in 883 patients $(55 \%)$, and $\geq 3$ in 344 patients (21\%); BDI scores were $0-4$ in 265 patients (16\%), $0-5$ in 418 patients $(26 \%), \geq 5$ in 1,354 patients $(84 \%)$, and $\geq 6$ in 1,201 patients (74\%). Generally, patients with mMRC scores $\geq 2$ had slightly lower pre-bronchodilator $\mathrm{FEV}_{1}$ values compared with patients with mMRC 0-1 (Table 1). As expected, SGRQ total scores were higher in the patients with $\mathrm{mMRC}$ scores $\geq 2$. The percentages of patients in GOLD categories II, III, and IV differed between the patient subgroups defined by baseline mMRC scores $\geq 2(59.1 \%$, $40.1 \%$, and $0.8 \%$, respectively) or $0-1(70.4 \%, 29.3 \%$, and $0.1 \%$, respectively).

\section{Health status}

Tiotropium/olodaterol 5/5 $\mu$ g significantly improved SGRQ scores compared with placebo for patients with mMRC scores $0-1$ and $\geq 2$ (Figures 1 and 2 ), with adjusted mean treatment differences of $-4.20(95 \% \mathrm{CI}:-6.11,-2.29)$ and -5.11 (95\% CI: $-7.10,-3.11)$, respectively $(P<0.0001$ for the treatment comparison in each mMRC subgroup). When tiotropium/olodaterol was compared with tiotropium, there was a greater improvement in SGRQ score for patients with an mMRC score $\geq 2$ (adjusted mean treatment difference -3.44 [95\% CI: $-5.43,-1.46] ; P=0.0007$ ) than for patients with an mMRC score $0-1$ (adjusted mean treatment difference -0.71 [95\% CI: $-2.57,1.16] ; P=0.4584$ ) (Figure 2). Although similar trends in treatment differences were observed for change in SGRQ total score using a higher mMRC cutoff ( $0-2$ and $\geq 3$ ), the data for the $m M R C \geq 3$ subgroup exhibited wider CIs due to the smaller patient numbers in this subgroup compared with the mMRC $0-1, \geq 2$, and 0-2 subgroups (Figure 2). When BDI was used as an alternative symptom measure, the change in SGRQ total score was greater with tiotropium/olodaterol vs tiotropium or placebo in all subgroups (Figure 2). Sample sizes for the lower BDI score subgroups ( $0-5$ and $0-4)$ were small, and the treatment difference data were associated with wide CIs.

The SGRQ response rates were greater for tiotropium/ olodaterol vs tiotropium or placebo for patients with $\mathrm{mMRC}$ scores $0-1$ and $\geq 2$ (Figure 3 ). Again, for tiotropium/olodaterol vs tiotropium, the treatment differences in SGRQ response were more apparent in patients with more severe baseline dyspnea (mMRC $\geq 2$ OR 2.09 [95\% CI: 1.41, 3.10]; $P=0.0002)$ than those with less severe baseline dyspnea (mMRC 0-1 OR 1.13 [95\% CI: 0.75, 1.71]; $P=0.5654$ ). Similar trends were observed for the ORs for SGRQ response rate for tiotropium/olodaterol vs tiotropium for the higher mMRC cutoff ( $0-2$ and $\geq 3)$ and for the subgroups defined by BDI (Figure 3). Again, CIs were wide for those subgroups with smaller patient numbers.

\section{Dyspnea}

Dyspnea, measured by TDI score, was consistently improved with tiotropium/olodaterol vs placebo for patients with mMRC scores $0-1$ and $\geq 2$ (adjusted mean treatment difference 1.63 [95\% CI: 1.06, 2.20]; $P<0.0001$ and 1.60 [95\% CI: 1.09, 2.10]; $P<0.0001$, respectively) (Figure 4). Tiotropium/olodaterol also consistently improved TDI score vs tiotropium for patients with mMRC scores $0-1$ and $\geq 2$ (adjusted mean treatment difference 0.51 [95\% CI: -0.05 , 1.07]; $P=0.0746$ and 0.65 [95\% CI: $0.15,1.15] ; P=0.0115$, respectively). Similar results were obtained using a higher mMRC score cutoff ( $0-2$ and $\geq 3)$, as well as in the BDI subgroups (both cutoff values) (Figure 4). The ORs for TDI response rate were greater for tiotropium/olodaterol vs 
Table I Baseline demographics and characteristics for patients with a baseline mMRC score of $0-I$ and $\geq 2$

\begin{tabular}{|c|c|c|}
\hline & mMRC $0-I(n=736)$ & $m M R C \geq 2(n=883)$ \\
\hline Male, n (\%) & $465(63.2)$ & $521(59.0)$ \\
\hline Mean (SD) age, years & $64.6(8.2)$ & $64.9(8.5)$ \\
\hline \multicolumn{3}{|l|}{ Race, $n(\%)$} \\
\hline White & $711(96.6)$ & $831(94.1)$ \\
\hline American Indian/Alaskan native & $I(0.1)$ & $4(0.5)$ \\
\hline Asian & $3(0.4)$ & $\mathrm{I}(0.1)$ \\
\hline Black/African American & $21(2.9)$ & $46(5.2)$ \\
\hline Native Hawaiian/Pacific Islander & $0(0.0)$ & $\mathrm{I}(0 . \mathrm{I})$ \\
\hline Mean (SD) body mass index, $\mathrm{kg} / \mathrm{m}^{2}$ & $27.2(5.3)$ & $28.5(6.2)$ \\
\hline \multicolumn{3}{|l|}{ Smoking status, n (\%) } \\
\hline Ex-smoker & $395(53.7)$ & $462(52.3)$ \\
\hline Current smoker & $34 I(46.3)$ & $421(47.7)$ \\
\hline \multicolumn{3}{|l|}{ mMRC, n (\%) } \\
\hline 0 & $117(15.9)$ & - \\
\hline I & $619(84.1)$ & - \\
\hline 2 & - & $539(6 \mid .0)$ \\
\hline 3 & - & $298(33.7)$ \\
\hline 4 & - & $46(5.2)$ \\
\hline Mean (SD) BDI & $7.3(1.9)$ & $5.8(2.0)$ \\
\hline \multicolumn{3}{|l|}{ Mean (SD) pre-bronchodilator screening } \\
\hline $\mathrm{FEV}_{1}, \mathrm{~L}$ & $1.439(0.499)$ & $1.268(0.470)$ \\
\hline \multicolumn{3}{|l|}{ Mean (SD) post-bronchodilator screening } \\
\hline $\mathrm{FEV}_{1}, \mathrm{~L}$ & $1.633(0.5 \mathrm{I} 2)$ & $1.453(0.482)$ \\
\hline$\%$ of predicted normal FEV, & $57.274(12.452)$ & $53.252(12.814)$ \\
\hline FEV , change from pre- to post-bronchodilator, L & $0.194(0.149)$ & $0.185(0.15 \mathrm{I})$ \\
\hline FVC, L & $3.227(0.884)$ & $2.967(0.864)$ \\
\hline $\mathrm{FEV}_{\mathrm{I}} / \mathrm{FVC}, \%$ & $51.083(10.17 \mathrm{I})$ & $49.670(10.596)$ \\
\hline \multicolumn{3}{|l|}{ GOLD, n (\%) } \\
\hline $\mathrm{I}(\geq 80 \%)$ & $I(0.1)$ & $0(0.0)$ \\
\hline $2(50-<80 \%)$ & $518(70.4)$ & $522(59.1)$ \\
\hline $3(30-<50 \%)$ & $216(29.3)$ & $354(40.1)$ \\
\hline $4(<30 \%)$ & $I(0 . I)$ & $7(0.8)$ \\
\hline Baseline pulmonary medication, $\mathrm{n}(\%)$ & $562(76.4)$ & $677(76.7)$ \\
\hline SAMA & $45(6.1)$ & $79(8.9)$ \\
\hline LAMA & $262(35.6)$ & $298(33.7)$ \\
\hline SABA & $370(50.3)$ & $447(50.6)$ \\
\hline LABA & $266(36.1)$ & $363(4 I . I)$ \\
\hline ICS & $256(34.8)$ & $352(39.9)$ \\
\hline Xanthines & $5(0.7)$ & $30(3.4)$ \\
\hline Mean (SE) SGRQ total score & $35.2(0.6)$ & $48.9(0.6)$ \\
\hline \multicolumn{3}{|l|}{ GOLD, n (\%) } \\
\hline A & $486(66.0)$ & $0(0.0)$ \\
\hline B & $0(0.0)$ & $483(54.7)$ \\
\hline C & $250(34.0)$ & $0(0.0)$ \\
\hline $\mathrm{D}$ & $0(0.0)$ & $400(45.3)$ \\
\hline
\end{tabular}

Abbreviations: BDI, baseline dyspnea index; FEV , forced expiratory volume in I second; GOLD, Global Initiative for Chronic Obstructive Lung Disease; ICS, inhaled corticosteroid; LABA, long-acting $\beta_{2}$-agonist; LAMA, long-acting muscarinic antagonist; mMRC, modified Medical Research Council dyspnea scale; SABA, short-acting $\beta_{2}-$ agonist; SAMA, short-acting muscarinic antagonist; SE, standard error; SGRQ, St George's Respiratory Questionnaire. 


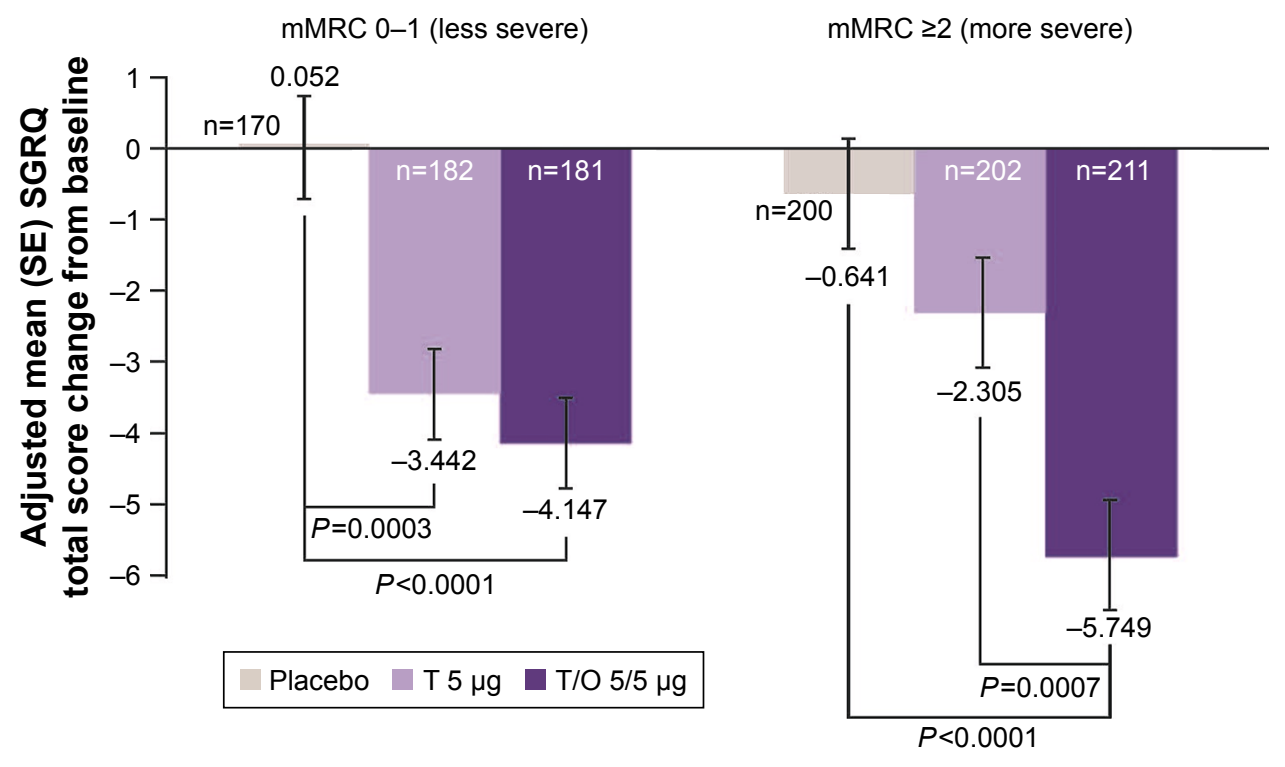

Figure I Adjusted mean change from baseline in SGRQ total score after 12 weeks for T/O $5 / 5 \mu \mathrm{g}$, T $5 \mu \mathrm{g}$, and placebo according to baseline dyspnea severity. Note: $P$-values shown for comparisons where the treatment difference reached significance.

Abbreviations: mMRC, modified Medical Research Council dyspnea score; O, olodaterol; SE, standard error; SGRQ, St George's Respiratory Questionnaire; $\mathrm{T}$, tiotropium.

tiotropium or placebo for patients with mMRC score $0-1$ or $\geq 2$, as well as with a higher mMRC cutoff and all BDI subgroups (Figure 4).

\section{Lung function}

There were improvements in lung function (trough $\mathrm{FEV}_{1}$ ) with tiotropium/olodaterol vs tiotropium or placebo in patients with $\mathrm{mMRC}$ scores $0-1$ and $\geq 2$ (Figure 5). Lung function also improved with tiotropium/olodaterol vs tiotropium or placebo in groups stratified by the higher mMRC cutoff, except for the tiotropium/olodaterol vs tiotropium comparison for patients with $\mathrm{mMRC} \geq 3$ (Figure 5). Lung function improvements with tiotropium/olodaterol compared with placebo were larger in less symptomatic patients assessed by BDI (data not shown), but not as measured by baseline mMRC. For tiotropium/olodaterol compared with tiotropium, this pattern was observed both for $\mathrm{mMRC}$ and BDI subgroups.

\section{Relationship between baseline lung function and symptoms as a predictor of SGRQ response}

Multiple logistic regression analysis of data for the full analysis population was performed to explore the combined effect of baseline lung function and baseline symptom severity on SGRQ response after 12 weeks of treatment, using a logistic regression model that included the covariates of GOLD stage (III vs II) and mMRC ( $\geq 2$ vs $0-1$ ), as well as treatment to adjust for known treatment differences and differences in baseline lung function. Baseline lung function (via GOLD stage) and baseline symptom severity had no effect on SGRQ response rate in the full analysis population (see Figure S2A). Multiple logistic regression analysis of data for the tiotropium/olodaterol $5 / 5 \mu \mathrm{g}$ treatment group only did not indicate that baseline lung function had an effect on SGRQ response rate after 12 weeks (GOLD III vs GOLD II OR 0.88 [95\% CI: 0.58, 1.34]; $P=0.5637$ ). However, baseline mMRC score was significantly associated with SGRQ response rate, with patients with greater baseline symptom burden exhibiting higher SGRQ response rates (mMRC $\geq 2$ vs $0-1$ OR 1.61 [95\% CI: 1.07, 2.41]; $P=0.0211$ ) (see Figure S2B).

\section{Discussion}

The approach to COPD therapy has been suggested to be optimized by a multidimensional approach to characterize disease severity and impact. The GOLD therapeutic strategy suggests differential pharmacotherapeutic approaches as a function of symptom burden. ${ }^{1}$ This and other therapeutic strategies $^{3}$ recommend regular maintenance treatment with a LAMA or LABA (Group B). ${ }^{1}$ Numerous studies have shown that the combination of LAMA and LABA provides a greater improvement in lung function, as well as a greater decrease in symptoms vs placebo and the individual bronchodilators. ${ }^{22,23}$ Whether single or dual bronchodilation should be used as first-line therapy for symptomatic patients remains unclear. 


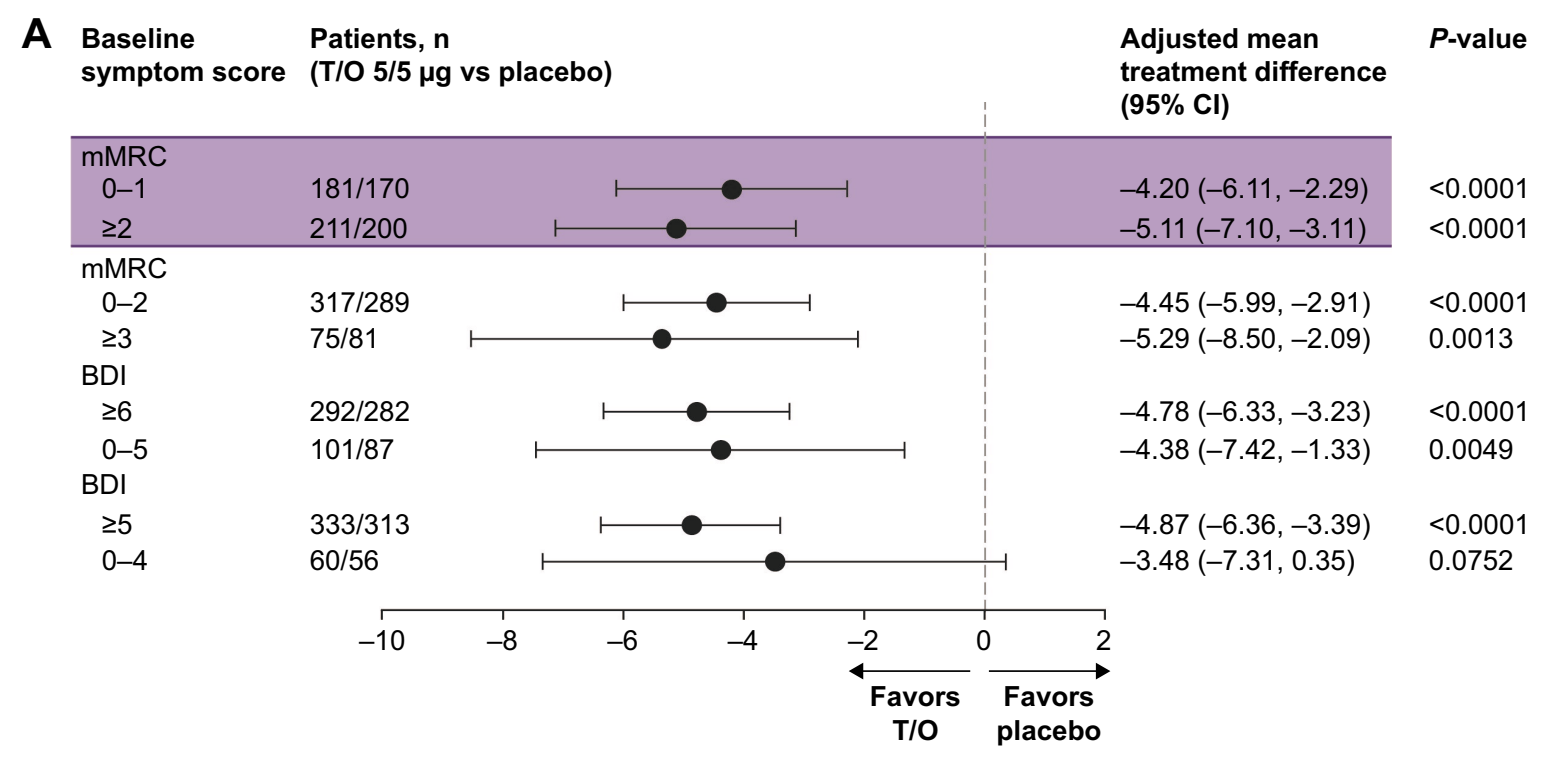

$\begin{array}{ll}\text { B } \begin{array}{ll}\text { Baseline } \\ \text { symptom score }\end{array} & \begin{array}{l}\text { Patients, } \mathrm{n} \\ \text { (T/O } 5 / 5 \mu \mathrm{g} \text { vs T } 5 \mu \mathrm{g})\end{array}\end{array}$

Adjusted mean $\quad P$-value

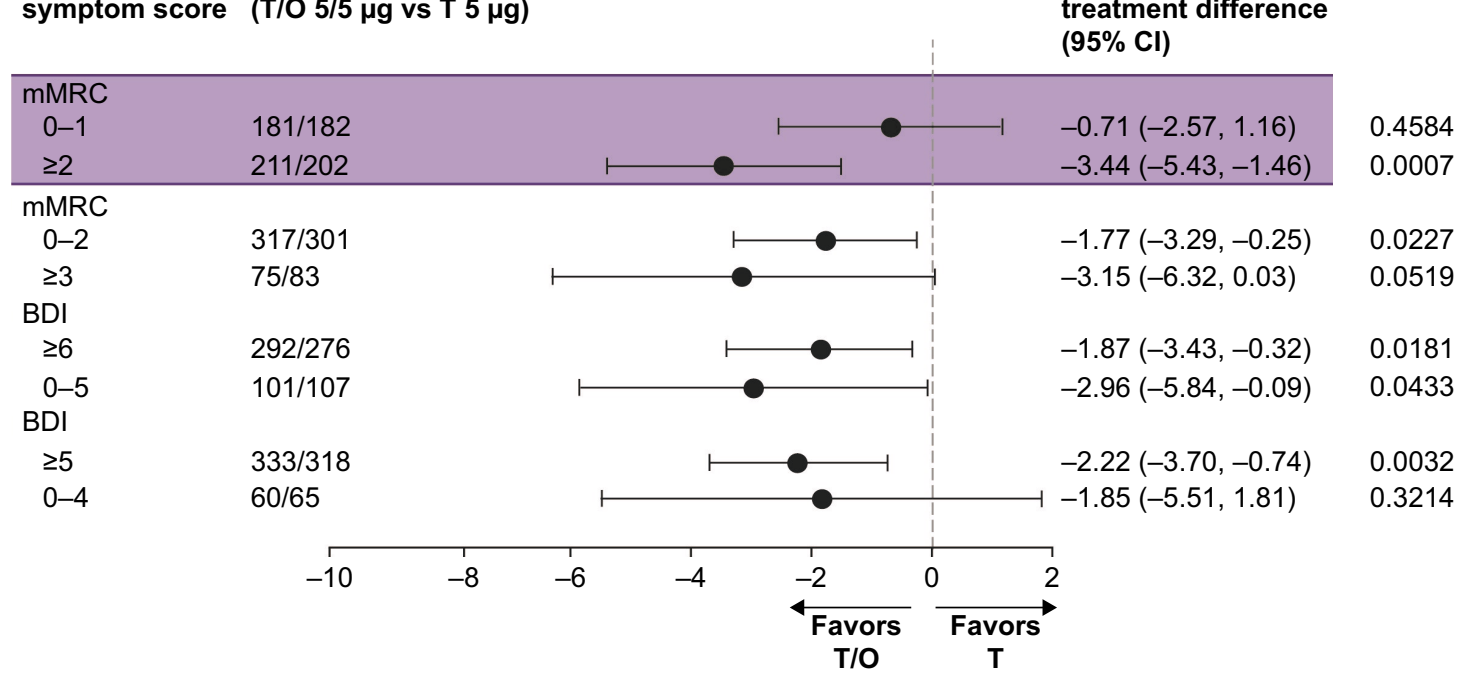

Figure 2 Forest plot of mean treatment difference in change in SGRQ total score according to baseline dyspnea severity following treatment with (A) T/O 5/5 $\mu \mathrm{g}$ vs placebo and (B) T/O $5 / 5 \mu \mathrm{g}$ vs T $5 \mu \mathrm{g}$.

Abbreviations: BDI, baseline dyspnea index; mMRC, modified Medical Research Council dyspnea score; O, olodaterol; SGRQ, St George's Respiratory Questionnaire; T, tiotropium.
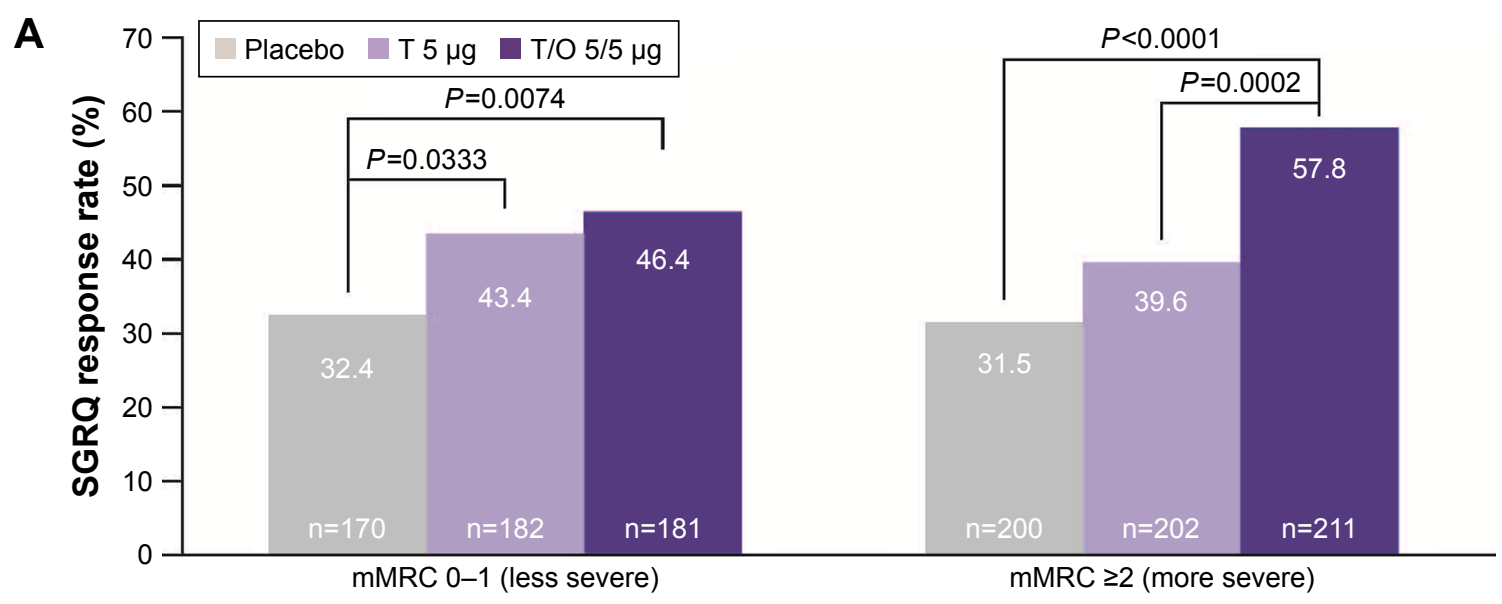

Figure 3 (Continued) 


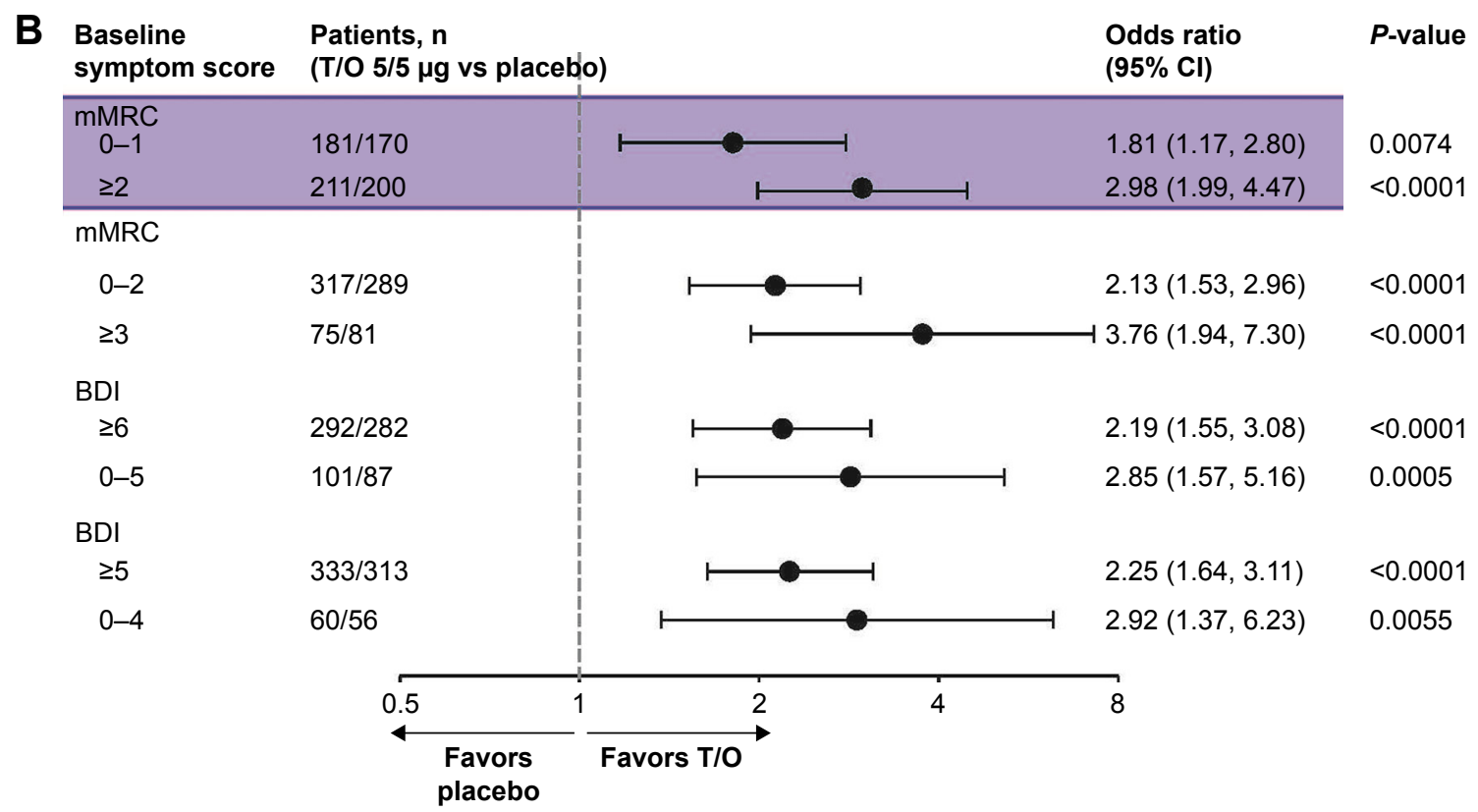

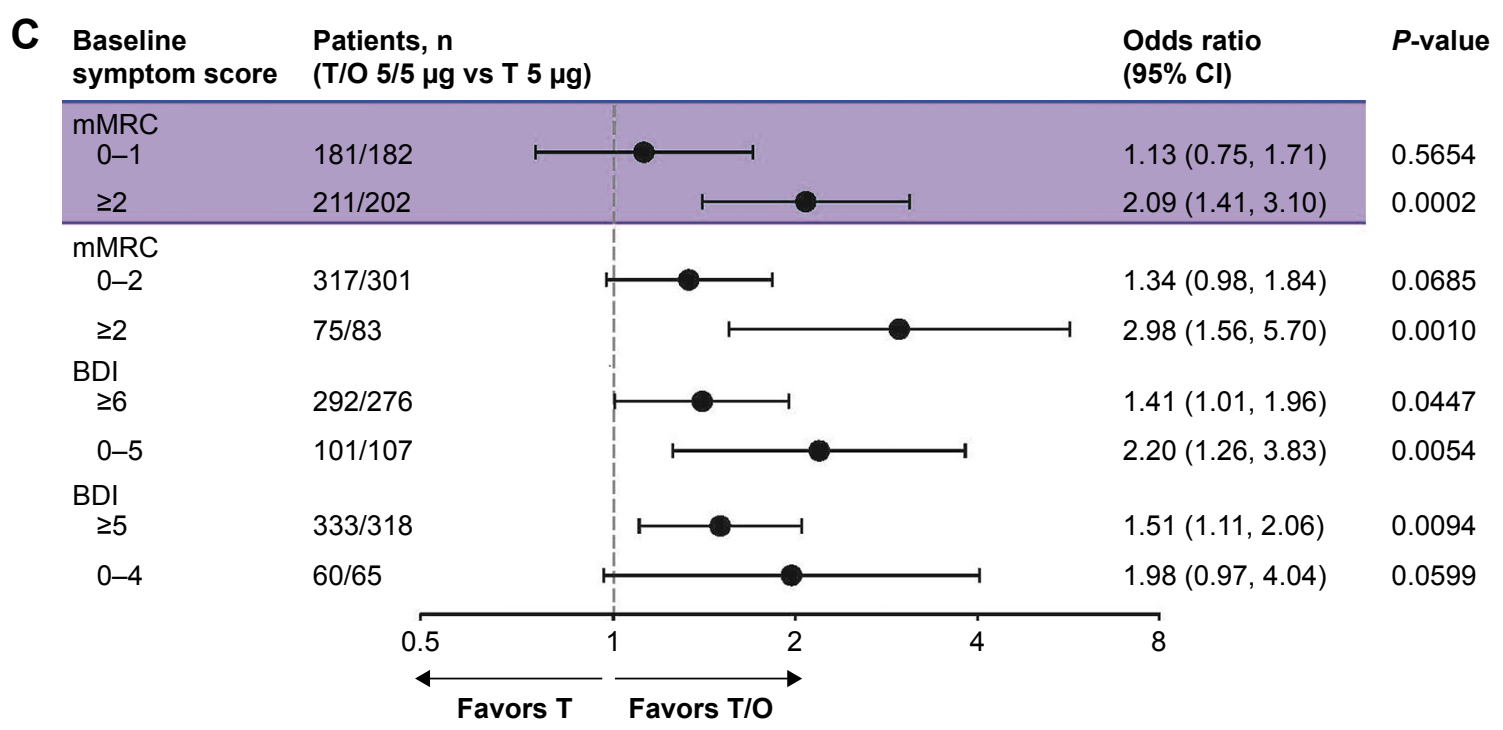

Figure 3 (A) SGRQ response rate for T/O $5 / 5 \mu \mathrm{g}$, T $5 \mu \mathrm{g}$, and placebo according to baseline dyspnea severity ( $P$-values shown for comparisons where the treatment difference reached significance), and (B) forest plot of ORs for SGRQ response rate according to baseline dyspnea severity following treatment with $\mathrm{T} / \mathrm{O} 5 / 5 \mu \mathrm{g}$ vs placebo and (C) T/O $5 / 5 \mu \mathrm{g}$ vs T $5 \mu \mathrm{g}$.

Abbreviations: BDI, baseline dyspnea index; mMRC, modified Medical Research Council dyspnea score; O, olodaterol; SGRQ, St George's Respiratory Questionnaire; T, tiotropium.

Our analyses confirmed that patients with COPD with more severe dyspnea at baseline, measured using the mMRC scale, had a greater response to tiotropium/olodaterol relative to tiotropium alone in both SGRQ total score and SGRQ responder rate. Importantly, this difference between tiotropium/olodaterol and tiotropium in SGRQ responder rate was apparent for two mMRC cutoffs ( $0-1$ versus $\geq 2$, and $0-2$ versus $\geq 3$ ) and was qualitatively similar in patients stratified by BDI. Interestingly, tiotropium/olodaterol improved dyspnea compared with tiotropium alone or placebo using both TDI score and TDI responder rate, regardless of baseline symptom status. Overall, these results suggest that patients with higher degrees of baseline symptoms, measured using mMRC, gain added clinical benefit with tiotropium/olodaterol compared with tiotropium alone for improvements in health-related health status, assessed by SGRQ; this additional benefit was less robust in patients with lesser degrees of baseline symptoms. However, in the case of symptoms measured by TDI, tiotropium/olodaterol consistently provided better improvement than tiotropium alone regardless of the degree of baseline symptoms. 
The relative lung function (trough $\mathrm{FEV}_{1}$ ) response with tiotropium/olodaterol vs tiotropium was greater in patients with less severe symptoms at baseline. However, patients with less severe symptoms had less severe airflow obstruction at baseline. The differential lung function response may therefore reflect the different proportions of patients with GOLD II vs III/IV impairment at baseline, and is consistent with previous findings from the trial program of improved lung function response in patients with less severe lung function impairment at baseline. ${ }^{24-26}$ The greater FEV 1 response in patients with less severe dyspnea also reflects the larger improvement in $\mathrm{FEV}_{1}$ that is expected in patients with less severe airflow obstruction, rather than a unique inverse relationship between change in $\mathrm{FEV}_{1}$ and baseline dyspnea.
A multiple logistic regression analysis, including baseline lung function and symptom severity together as predictors of SGRQ response, provided additional insights. Overall, averaged across all treatment groups, baseline lung function and symptom severity did not appear to predict SGRQ response. On the other hand, for those treated with tiotropium/ olodaterol, more severe symptoms at baseline related to a greater likelihood of identifying SGRQ responders. Baseline lung function did not appear to predict SGRQ response. This analysis provides reassurance that the differences in SGRQ response observed between the groups with less and more severe symptoms at baseline are not a result of the observed differential baseline lung function between these groups. Despite numerous groups suggesting the benefit of

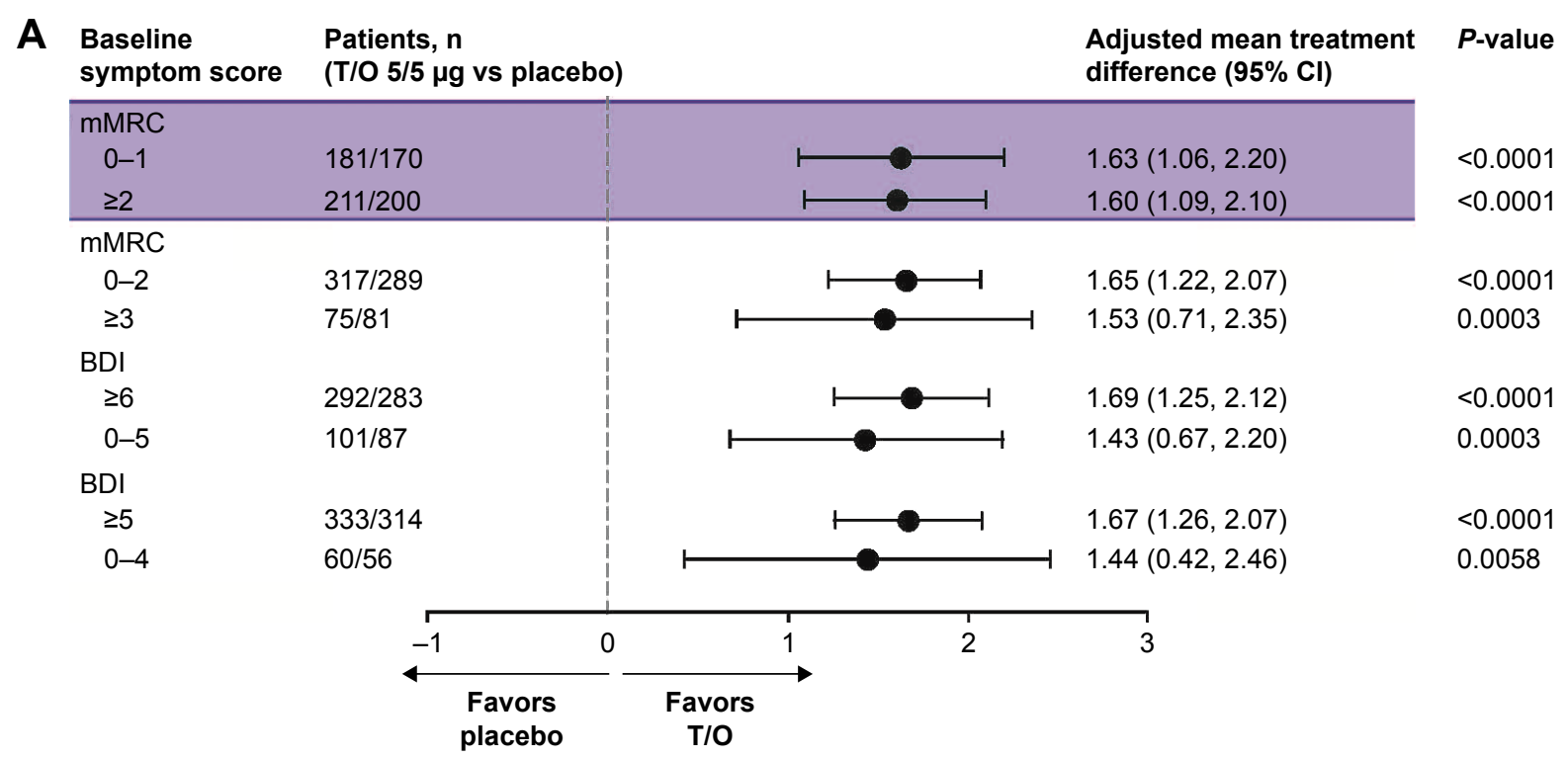

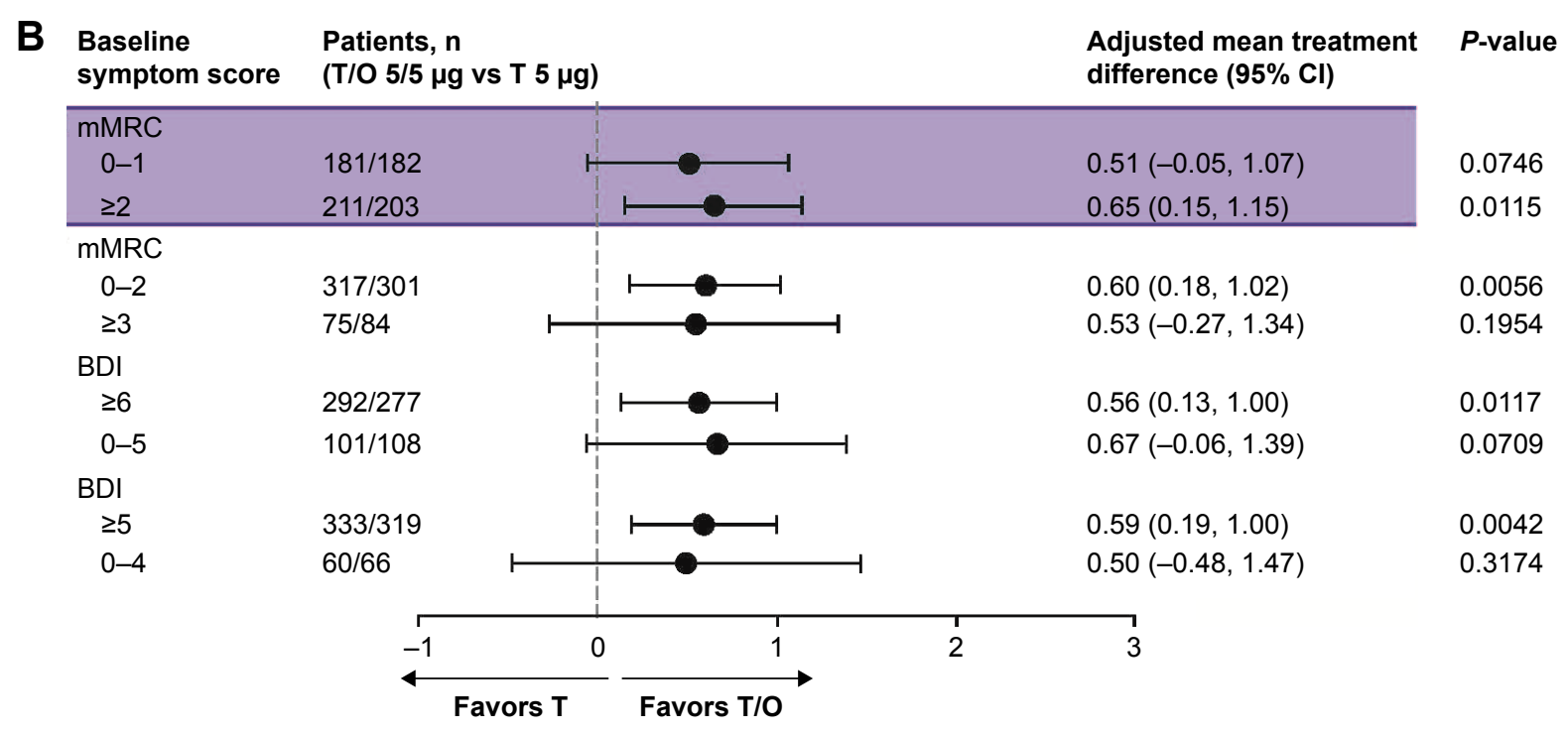

Figure 4 (Continued) 


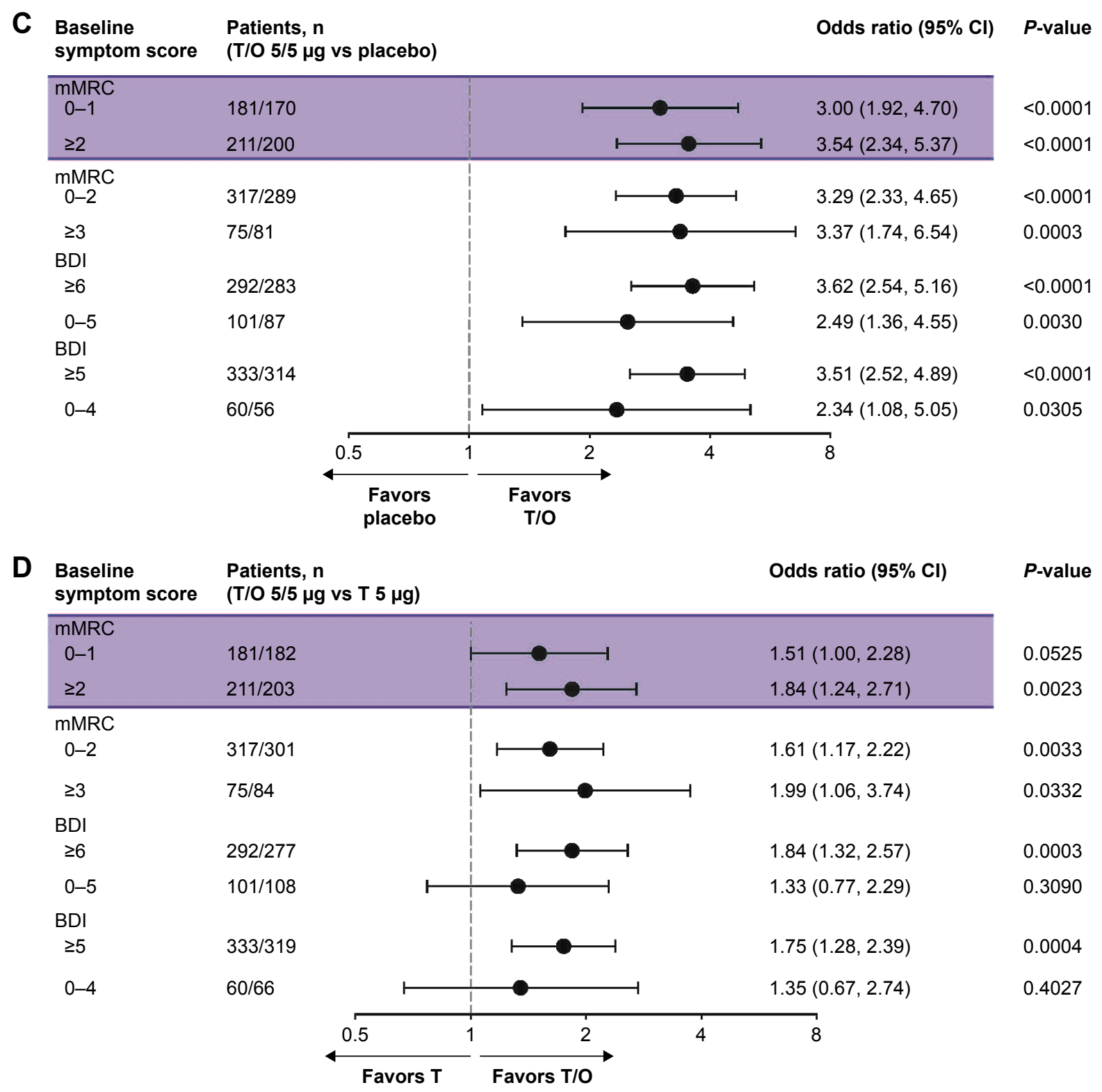

Figure 4 Forest plots of mean treatment difference in change in TDI focal score according to baseline dyspnea severity following treatment with (A) T/O $5 / 5 \mu \mathrm{g}$ v placebo and (B) T/O 5/5 $\mu \mathrm{g}$ vs T $5 \mu \mathrm{g}$, and forest plots of OR for TDI response rate according to baseline dyspnea severity following treatment with (C) T/O $5 / 5 \mu \mathrm{g}$ vs placebo and (D) T/O $5 / 5 \mu \mathrm{g}$ vs T $5 \mu \mathrm{g}$. TDI responder is defined as TDI focal score $\geq$ I better than baseline TDI focal score.

Abbreviations: BDI, baseline dyspnea index; mMRC, modified Medical Research Council dyspnea score; O, olodaterol; T, tiotropium; TDI, transition dyspnea index.

combining LAMA and LABA compared with the individual monocomponents, the observed absolute improvements in dyspnea and health status have often not consistently exceeded the minimum clinically important difference for the instruments used to measure these outcomes. ${ }^{22,23,27}$ Our data suggest that baseline symptom burden may have a strong influence on these results. Previous studies have varied in the inclusion of study patients with a broad range of baseline symptoms. ${ }^{28-37}$

These data provide clinically relevant information for future therapeutic strategy recommendations and, more importantly, for clinicians aiding patients with COPD. For example, the GOLD document suggests baseline symptoms as a guide for the use of long-acting bronchodilators; a LAMA or LABA is suggested as a first option for patients with higher mMRC or COPD Assessment Test scores. ${ }^{1}$ The combination of a LAMA and LABA is suggested as a potential option for those with severe breathlessness. Our data provide support for this statement and offer additional insights. Tiotropium/olodaterol provides overall lung function and health status benefits regardless of greater baseline dyspnea burden (measured by mMRC or BDI) when compared with 


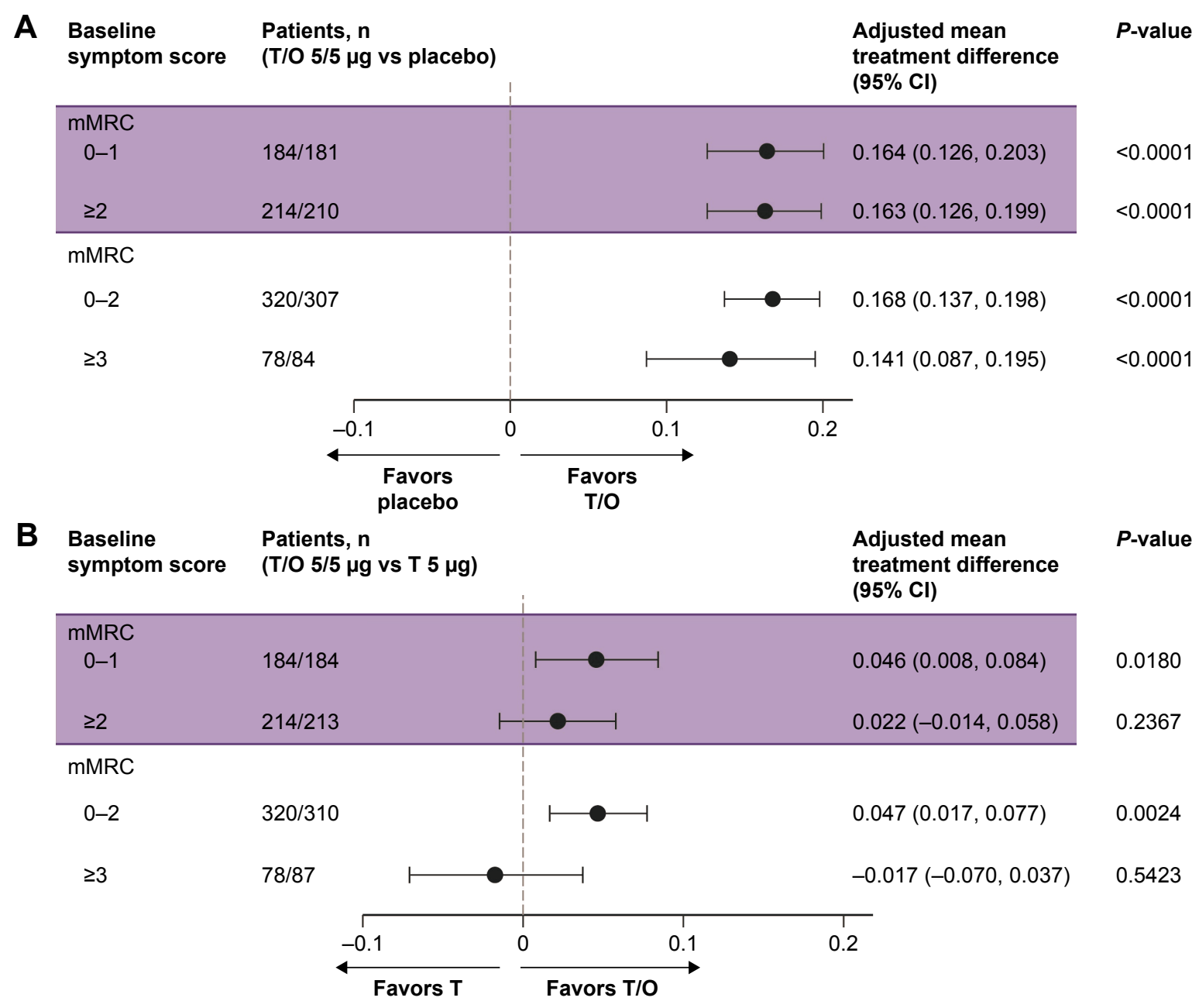

Figure 5 Forest plots of adjusted mean treatment difference in change in trough FEV $(\mathrm{L})$ according to baseline dyspnea severity following treatment with $(\mathbf{A}) \mathrm{T} / \mathrm{O} 5 / 5 \mu \mathrm{g}$ vs placebo and (B) $\mathrm{T} / \mathrm{O} 5 / 5 \mu \mathrm{g}$ vs $\mathrm{T} 5 \mu \mathrm{g}$.

Abbreviations: $\mathrm{FEV}_{1}$, forced expiratory volume in I second; mMRC, modified Medical Research Council dyspnea score; O, olodaterol; T, tiotropium.

tiotropium alone. Future studies of treatment-naïve patients, or those receiving only monotherapy, are needed to test escalation to LABA/LAMA, and this may be best tested in a real-world setting.

There are limitations to our work. This was a post hoc analysis with its attendant difficulties in interpretation. Our results should be considered hypothesis-generating and should be confirmed with well-designed prospective studies. The OTEMTO ${ }^{\circledR}$ studies used the GOLD I-IV categorization of COPD severity, as the A-D classification ${ }^{1}$ had not been published when the studies were designed and initiated. Importantly, these studies included GOLD II-III patients only, so whether these results apply to patients with COPD with more severe airflow obstruction is unclear. These were short-term studies that were not designed to examine exacerbations. As such, we are unable to examine the impact of baseline symptom burden on other clinically relevant end points.

\section{Conclusions}

Based on our post hoc analyses, improvements in health status (measured using SGRQ), symptoms (measured using TDI), and lung function were observed in both symptomatic and non-symptomatic patients following treatment with tiotropium/olodaterol. More severe dyspnea, assessed by mMRC, was associated with a larger SGRQ improvement for LAMA/LABA combination compared with a LAMA alone or placebo, but did not affect lung function improvement. These results suggest that patients with COPD with greater baseline dyspnea appear to derive greater health status benefit with a dual bronchodilator combination compared with a LAMA alone.

\section{Data sharing statement}

To ensure independent interpretation of clinical study results, Boehringer Ingelheim grants all external authors access to all 
relevant material, including participant-level clinical study data, and relevant material as needed by them to fulfill their role and obligations as authors under the ICMJE criteria.

Furthermore, clinical study documents (eg, study report, study protocol, statistical analysis plan) and participant clinical study data are available to be shared after publication of the primary manuscript in a peer-reviewed journal and if regulatory activities are complete and other criteria met per the BI Policy on Transparency and Publication of Clinical Study Data: https://trials.boehringer-ingelheim.com/ transparency policy.html.

Prior to providing access, documents will be examined, and, if necessary, redacted and the data will be de-identified, to protect the personal data of study participants and personnel, and to respect the boundaries of the informed consent of the study participants.

Clinical Study Reports and Related Clinical Documents can be requested via this link: https://trials.boehringeringelheim.com/trial results/clinical submission documents. $\underline{\mathrm{html}}$. All such requests will be governed by a Document Sharing Agreement.

Bona fide, qualified scientific and medical researchers may request access to de-identified, analyzable participant clinical study data with corresponding documentation describing the structure and content of the datasets. Upon approval, and governed by a Data Sharing Agreement, data are shared in a secured data-access system for a limited period of 1 year, which may be extended upon request.

Researchers should use https://clinicalstudydatarequest. com to request access to study data.

\section{Acknowledgments}

Medical writing assistance was provided by Gail Rickard, $\mathrm{PhD}$, of Complete HealthVizion, which was contracted and compensated by Boehringer Ingelheim Pharma $\mathrm{GmbH} \&$ Co. KG. The study was sponsored by Boehringer Ingelheim Pharma GmbH \& Co. KG.

\section{Author contributions}

FJM contributed to the design and conduct of the study, and wrote the first draft of the manuscript. RA, GTF, LB, and DS contributed to the design and conduct of the study. LG was involved in all aspects of the design, conduct, and data analysis of the study. FV provided statistical support and was involved in the data analysis of this post hoc study. All authors contributed to data analysis, drafting and revising the article, gave final approval of the version to be published, and agree to be accountable for all aspects of the work.

\section{Disclosure}

FJM reports grants from NHLBI during the conduct of the study, grants from National Institutes of Health, personal fees from Continuing Education, Forest Laboratories, GlaxoSmithKline, Nycomed/Takeda, AstraZeneca, Boehringer Ingelheim, Bellerophon Therapeutics (formerly Ikaria), Genentech, Novartis, Pearl, Roche, Sunovion, Theravance, CME Incite, Annenberg Center for Health Sciences at Eisenhower, Integritas, InThought, National Association for Continuing Education, Paradigm Medical Communications, LLC, PeerVoice, UpToDate, Haymarket Communications, Western Society of Allergy and Immunology, ProterixBio (formerly Bioscale), Unity Biotechnology, Concert Pharmaceuticals, Lucid, Methodist Hospital, Columbia University, Prime Healthcare Ltd, WebMD, PeerView Network, California Society of Allergy and Immunology, Chiesi, and Puerto Rico Thoracic Society, and advisory board participation for Janssen. RA reports grants and personal fees from AstraZeneca, Boehringer Ingelheim, and GlaxoSmithKline, and grants from Pearl Therapeutics. GTF reports consulting and advisory board fees from Boehringer Ingelheim, AstraZeneca, Pearl Therapeutics, Novartis, Forest, Sunovion, and Verona, consulting fees from Receptos, speaker fees from Boehringer Ingelheim, GlaxoSmithKline, AstraZeneca, Pearl Therapeutics, Forest, and Sunovion, and research grants from Boehringer Ingelheim, AstraZeneca, Pearl Therapeutics, Sunovion, Novartis, Theravance, Sanofi, Forest, and GlaxoSmithKline. LB reports advisory board participation or personal fees for lectures from ALK, Airsonett, AstraZeneca, Boehringer Ingelheim, Chiesi, GlaxoSmithKline, Novartis, Takeda, and Teva. FV is an employee of Boehringer Ingelheim. LG was an employee at the time of the conduct of the study, and is currently employed by CSL Behring. DS reports personal fees from Apellis, Cipla, Genentech, Peptinnovate, and Vectura (formerly Skyepharma), and grants and personal fees from AstraZeneca, Boehringer Ingelheim, Chiesi, Glenmark, Merck, Mundipharma, Novartis, Pfizer, Pulmatrix, Teva, Theravance, and Verona. The authors report no other conflicts of interest in this work.

\section{References}

1. Global Initiative for Chronic Obstructive Lung Disease. Global Strategy for the Diagnosis, Management, and Prevention of Chronic Obstructive Pulmonary Disease: 2018 Report.

2. Miravitlles M, Soler-Cataluña JJ, Calle M, et al. Spanish Guidelines for Management of Chronic Obstructive Pulmonary Disease (GesEPOC) 2017. Pharmacological treatment of stable phase. Arch Bronconeumol. 2017;53(6):324-335 
3. Rennard S, Thomashow B, Crapo J, et al. Introducing the COPD Foundation Guide for Diagnosis and Management of COPD, recommendations of the COPD Foundation. COPD. 2013;10(3):378-389.

4. Maltais F, Hamilton A, Marciniuk D, et al. Improvements in symptomlimited exercise performance over $8 \mathrm{~h}$ with once-daily tiotropium in patients with COPD. Chest. 2005;128(3):1168-1178.

5. O’Donnell DE, Flüge T, Gerken F, et al. Effects of tiotropium on lung hyperinflation, dyspnoea and exercise tolerance in COPD. Eur Respir J. 2004;23(6):832-840.

6. Tashkin DP, Celli B, Senn S, et al. A 4-year trial of tiotropium in chronic obstructive pulmonary disease. N Engl J Med. 2008;359(15): 1543-1554.

7. Vogelmeier C, Hederer B, Glaab T, et al. Tiotropium versus salmeterol for the prevention of exacerbations of COPD. $N$ Engl J Med. 2011; 364(12):1093-1103.

8. Casaburi R, Mahler DA, Jones PW, et al. A long-term evaluation of once-daily inhaled tiotropium in chronic obstructive pulmonary disease. Eur Respir J. 2002;19(2):217-224.

9. Bateman ED, Tashkin D, Siafakas N, et al. A one-year trial of tiotropium Respimat plus usual therapy in COPD patients. Respir Med. 2010; 104(10):1460-1472.

10. Yohannes AM, Willgoss TG, Vestbo J. Tiotropium for treatment of stable COPD: a meta-analysis of clinically relevant outcomes. Respir Care. 2011;56(4):477-487.

11. Ferguson GT, Feldman GJ, Hofbauer P, et al. Efficacy and safety of olodaterol once daily delivered via Respimat ${ }^{\mathbb{E}}$ in patients with GOLD 2-4 COPD: results from two replicate 48-week studies. Int J Chron Obstruct Pulmon Dis. 2014;9:629-645.

12. Koch A, Pizzichini E, Hamilton A, et al. Lung function efficacy and symptomatic benefit of olodaterol once daily delivered via Respimat ${ }^{\circledR}$ versus placebo and formoterol twice daily in patients with GOLD 2-4 COPD: results from two replicate 48-week studies. Int J Chron Obstruct Pulmon Dis. 2014;9:697-714.

13. Feldman GJ, Bernstein JA, Hamilton A, Nivens MC, Korducki L, Laforce C. The 24-h FEV1 time profile of olodaterol once daily via Respimat ${ }^{\circledR}$ and formoterol twice daily via Aerolizer ${ }^{\circledR}$ in patients with GOLD 2-4 COPD: results from two 6-week crossover studies. Springerplus. 2014;3:419.

14. Lange P, Aumann J, Hamilton A, Tetzlaff K, Ting N. The 24-hour lung function time profile of olodaterol once daily versus placebo and tiotropium in patients with moderate to very severe chronic obstructive pulmonary disease. J Pulm Respir Med. 2014;4:196.

15. Buhl R, Maltais F, Abrahams R, et al. Tiotropium and olodaterol fixeddose combination versus mono-components in COPD (GOLD 2-4). Eur Respir J. 2015;45(4):969-979.

16. Beeh KM, Westerman J, Kirsten AM, et al. The 24-h lung-function profile of once-daily tiotropium and olodaterol fixed-dose combination in chronic obstructive pulmonary disease. Pulm Pharmacol Ther. 2015; 32:53-59.

17. Singh D, Ferguson GT, Bolitschek J, et al. Tiotropium + olodaterol shows clinically meaningful improvements in quality of life. Respir Med. 2015;109(10):1312-1319.

18. Martinez FJ, Abrahams R, Ferguson GT, et al. Effects of symptom severity at baseline on lung-function and SGRQ responses in the OTEMTO ${ }^{\circledR}$ studies. Am J Respir Crit Care Med. 2016;193:A6787.

19. Mahler DA, Waterman LA, Ward J, Mccusker C, Zuwallack R, Baird JC. Validity and responsiveness of the self-administered computerized versions of the baseline and transition dyspnea indexes. Chest. 2007; 132(4):1283-1290.

20. Mahler DA, Ward J, Waterman LA, Mccusker C, Zuwallack R, Baird JC. Patient-reported dyspnea in COPD reliability and association with stage of disease. Chest. 2009;136(6):1473-1479.

21. Perez T, Burgel PR, Paillasseur JL, et al. Modified Medical Research Council scale vs Baseline Dyspnea Index to evaluate dyspnea in chronic obstructive pulmonary disease. Int J Chron Obstruct Pulmon Dis. 2015;10:1663-1672.
22. Farne HA, Cates CJ. Long-acting beta2-agonist in addition to tiotropium versus either tiotropium or long-acting beta2-agonist alone for chronic obstructive pulmonary disease. Cochrane Database Syst Rev. 2015;22(10):CD008989.

23. Banerji D, Mahler DA, Hanania NA. Efficacy and safety of LABA/ LAMA fixed-dose combinations approved in the US for the management of COPD. Expert Rev Respir Med. 2016;10(7):767-780.

24. Ferguson GT, Fležar M, Korn S, et al. Efficacy of tiotropium + olodaterol in patients with chronic obstructive pulmonary disease by initial disease severity and treatment intensity: a post hoc analysis. Adv Ther. 2015;32(6):523-536.

25. Singh D, Ferguson GT, Bolitschek J. Tiotropium + olodaterol fixed-dose combination shows clinically meaningful improvements in quality of life versus placebo. Eur Respir J. 2015;46:PA2958.

26. Singh D, Gaga M, Schmidt O, et al. Effects of tiotropium + olodaterol versus tiotropium or placebo by COPD disease severity and previous treatment history in the OTEMTO ${ }^{\circledR}$ studies. Respir Res. 2016; 17(1):73.

27. Rodrigo GJ, Neffen H. A systematic review of the efficacy and safety of a fixed-dose combination of umeclidinium and vilanterol for the treatment of COPD. Chest. 2015;148(2):397-407.

28. Tashkin DP, Pearle J, Iezzoni D, Varghese ST. Formoterol and tiotropium compared with tiotropium alone for treatment of COPD. COPD. 2009;6(1):17-25

29. Wedzicha JA, Decramer M, Ficker JH, et al. Analysis of chronic obstructive pulmonary disease exacerbations with the dual bronchodilator QVA149 compared with glycopyrronium and tiotropium (SPARK): a randomised, double-blind, parallel-group study. Lancet Respir Med. 2013;1(3):199-209.

30. Bateman ED, Ferguson GT, Barnes N, et al. Dual bronchodilation with QVA149 versus single bronchodilator therapy: the SHINE study. Eur Respir J. 2013;42(6):1484-1494.

31. Donohue JF, Maleki-Yazdi MR, Kilbride S, Mehta R, Kalberg C, Church A. Efficacy and safety of once-daily umeclidinium/vilanterol 62.5/25 mcg in COPD. Respir Med. 2013;107(10):1538-1546.

32. Celli B, Crater G, Kilbride S, et al. Once-daily umeclidinium/vilanterol 125/25 mcg in COPD: a randomized, controlled study. Chest. 2014; 145(5):981-991.

33. Decramer M, Anzueto A, Kerwin E, et al. Efficacy and safety of umeclidinium plus vilanterol versus tiotropium, vilanterol, or umeclidinium monotherapies over 24 weeks in patients with chronic obstructive pulmonary disease: results from two multicentre, blinded, randomised controlled trials. Lancet Respir Med. 2014;2(6):472-486.

34. Dahl R, Chung KF, Buhl R, et al. Efficacy of a new once-daily longacting inhaled beta2-agonist indacaterol versus twice-daily formoterol in COPD. Thorax. 2010;65(6):473-479.

35. Bateman ED, Chapman KR, Singh D, et al. Aclidinium bromide and formoterol fumarate as a fixed-dose combination in COPD: pooled analysis of symptoms and exacerbations from two six-month, multicentre, randomised studies (ACLIFORM and AUGMENT). Respir Res. 2015;16:92.

36. Mahler DA, Kerwin E, Ayers T, et al. FLIGHT1 and FLIGHT2: efficacy and safety of QVA149 (indacaterol/glycopyrrolate) versus its monocomponents and placebo in patients with chronic obstructive pulmonary disease. Am J Respir Crit Care Med. 2015;192(9): 1068-1079.

37. Singh D, Jones PW, Bateman ED, et al. Efficacy and safety of aclidinium bromide/formoterol fumarate fixed-dose combinations compared with individual components and placebo in patients with COPD (ACLIFORM-COPD): a multicentre, randomised study. BMC Pulm Med. 2014;14(1):178. 


\section{Supplementary materials \\ Supplementary SI}

Details of ethics committees for participating centres

UZ Brussel, Commissie voor Medische Ethiek, Laarbeeklaan

101, 1090 Brussel, Belgium

IRB Services, 372 Holland Trail, Suite 300, Aurora, Ontario, L4G 0A5, Canada

Health Research Ethics Board of Alberta Clinical Trials Committee, 1500, 10104 - 103 Avenue NW, Edmonton, Alberta, T5J 4A7, Canada

Etiska komise pro multicentricka klinicka hodnoceni, Fakultni nemocnice v, Motole V Uvalu 84, 15006, Praha 5 , Czech Republic

De Videnskabsetiske Komitéer for Region Syddanmark Sundhedssekretariatet, Damhaven 12, 7100 Vejle, Denmark

Varsinais-Suomen sairaanhoitopiirin kuntayhtymän eettinen toimikunta, Kiinamyllynkatu 4-8, 20521 Turku, Finland

Ethikkommission der Ärztekammer Schleswig-Holstein, Bismarckallee 8-12, 23795 Bad Segeberg, Germany

NRES Committee North West - Greater Manchester Central, 3rd Floor, Barlow House, 4 Minshull Street, Manchester, M1 3DZ, UK

Comité Ético de Investigación Clínica del Hospital Universitario Puerta de Hierro Majadahonda, C/Joaquín Rodrigo, 2, 28222-Majadahonda, (Madrid) Spain

UCT Ethics Faculty of Health Sciences, Room E52-23, Groote Schuur Hospital, Old Main Building, Observatory, 7925, South Africa

Ste llenbosch Ethics, Health Research Ethics Committee Division of Research and Support, PO Box 19063, Tygerberg 7505, 021938 9677, South Africa

Pharma Ethics, 123 Amcor Road, Lyttelton Manor, Pretoria, South Africa

Chesapeake IRB, 6940 Columbia, Gateway Drive Suite 110, Columbia, MD 21046-3403, USA

Mercy St Vincent, Medical Center Adult IRB, 2213 Cherry Street, Toledo, OH 43608, USA
Sir Charles Gairdner, Human Research Ethics Committee, A Block, Hospital Avenue, Nedlands, Perth, Australia

Southern Adelaide Clinical Human Research Ethics Committee, Bedford Park 5042, Adelaide, Australia

Bellberry Human Research Ethics Committee, 129 Glen Osmond Road, Eastwood, Adelaide, Australia

Sydney Local Health District Human Research Ethics Committee - Concord Repatriation General Hospital, Sydney, Australia

CEC Ethikkommission des Landes Oberösterreich Wagner-Jauregg-Weg 15, 4020 Linz, Austria

LEC 43004, Ethikkommission des Landes Steiermark, Abt 8, FAGPSanitätsdirektion Amt der Steiermärkischen, Landesregierung, Friedrichgasse 9/E/28, 8010 Graz, Austria

EED Leoforos Mesogion, 284, P.C: 15562, Cholargos, Athens

Northern A Health and Disability Ethics Committee, Ministry of Health, 1-3 The Terrace, PO Box 5013, Wellington 6011, New Zealand

Regional komité for medisinsk og helsefaglig forskningsetikk (REK sør-øst), Sweden

CEC (LEC 42104 site): Eticka komisia Presovskeho, samospravneho kraja, Urad Presovskeho, samospravneho kraja, Namestie mieru 208001 Presov, Slovakia

LEC: Eticka komisia Narodny ustav tuberkulozy, plucnych, chorob a hrudnikovej chirurgie 05984 Vysne Hagy, Slovakia

LEC: Eticka komisia Urad Kosickeho, samospravneho kraja, Namestie Maratonu, Mieru 1, 04266 Kosice, Slovakia

LEC: Eticka komisia, Nemocnica s, poliklinikou sv. Jakuba, Bardejov, ul. Sv. Jakuba 21, 0850101 Bardejov, Slovakia

Regionala Etikprövningsnämnden, i Lund, Box 133, 221 00 Lund, Sweden. 


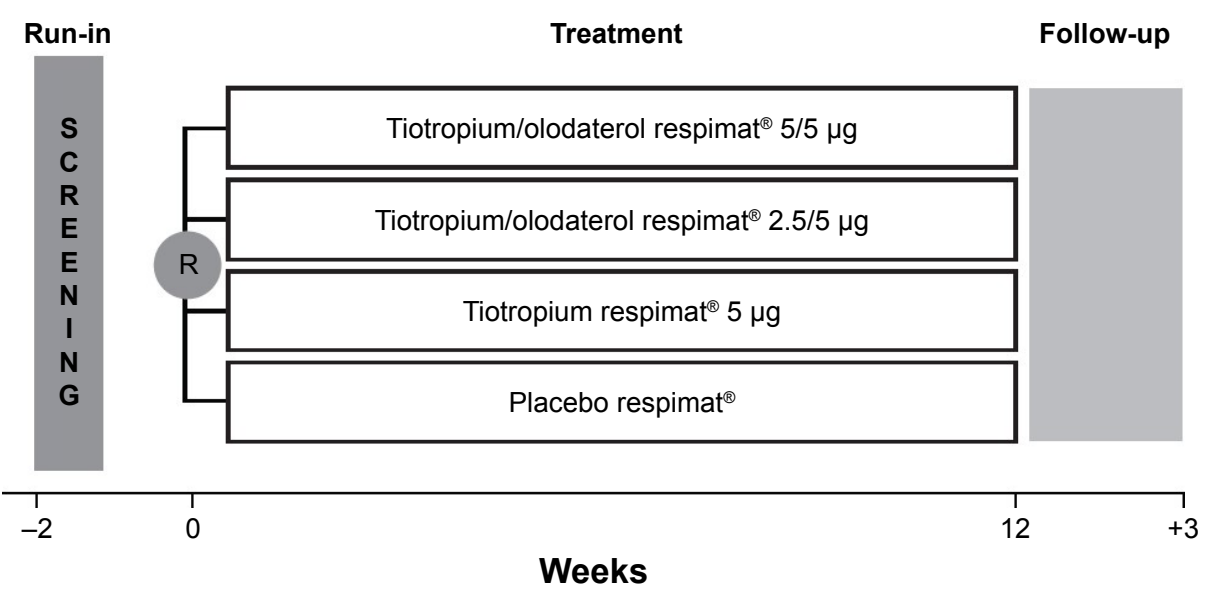

Figure SI Study design of OTEMTO ${ }^{\circledR} \mathrm{I}$ and 2.

Abbreviation: R, randomization.

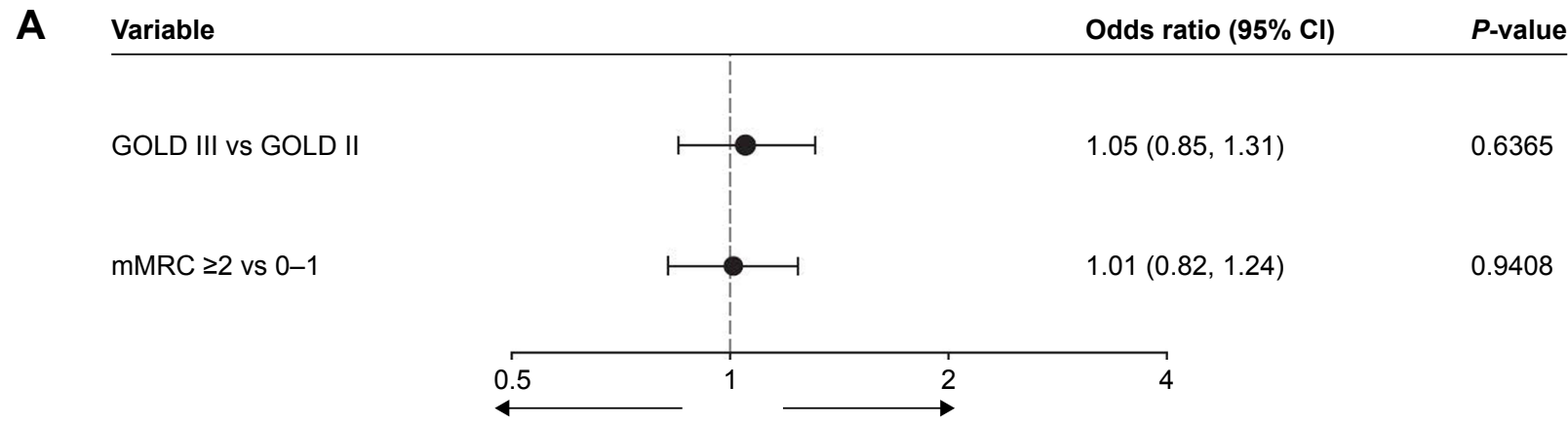

Lower SGRQ response in 1st category Higher SGRQ response in 1st category

Odd ratio $(95 \% \mathrm{Cl})$ for placebo vs T $5 \mu \mathrm{g}$ was $0.67(0.50,0.91) ; P=0.0090$, and T/O $5 / 5 \mu \mathrm{g}$ vs T $5 \mu \mathrm{g}$ was $1.58(1.19,2.10) ; P=0.0017$

B Variable

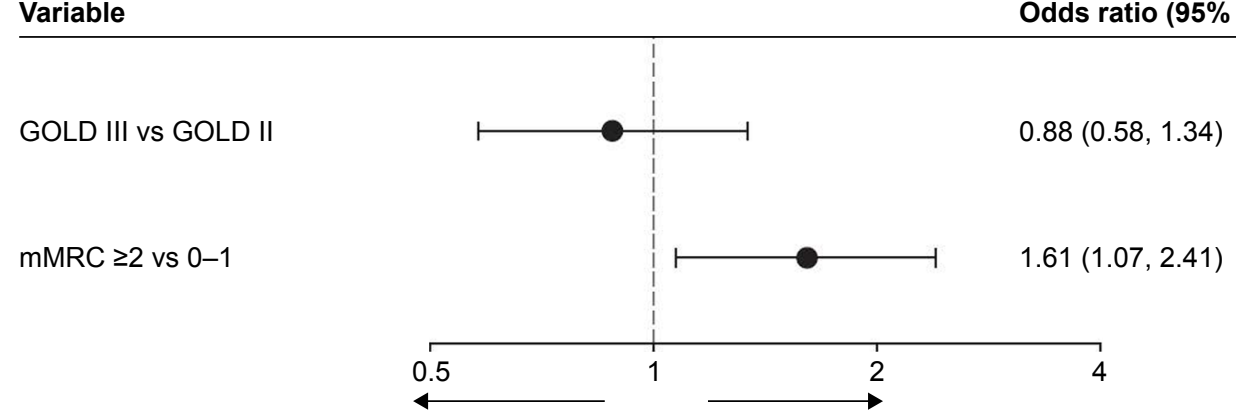

Lower SGRQ response in 1st category

Higher SGRQ response in 1st category

Figure S2 Forest plot of SGRQ response after 12 weeks versus baseline variables for $(\mathbf{A})$ all treatment groups and (B) T/O 5/5 $\mu \mathrm{g}$ treatment group.

Abbreviations: GOLD, Global Initiative for Chronic Obstructive Lung Disease; mMRC, modified Medical Research Council; O, olodaterol; SGRQ, St George's Respiratory Questionnaire; T, tiotropium.

International Journal of COPD

\section{Publish your work in this journal}

The International Journal of COPD is an international, peer-reviewed journal of therapeutics and pharmacology focusing on concise rapid reporting of clinical studies and reviews in COPD. Special focus is given to the pathophysiological processes underlying the disease, intervention programs, patient focused education, and self management protocols.

\section{Dovepress}

This journal is indexed on PubMed Central, MedLine and CAS. The manuscript management system is completely online and includes a very quick and fair peer-review system, which is all easy to use. Visit http://www.dovepress.com/testimonials.php to read real quotes from published authors.

Submit your manuscript here: http://www.dovepress.com/international-journal-of-chronic-obstructive-pulmonary-disease-journal 